\title{
Herd-level seroprevalence of Fasciola hepatica and Ostertagia ostertagi infection in dairy cattle population in the central and northeastern Poland
}

Sławomir J. Kowalczyk¹, Michał Czopowicz ${ }^{1 *}$, Corinna N. Weber ${ }^{2}$, Elisabeth Müller ${ }^{2}$, Tomasz Nalbert ${ }^{1}$, Andrzej Bereznowski ${ }^{1}$ and Jarosław Kaba ${ }^{1}$

\begin{abstract}
Background: Fasciola hepatica and Ostertagia ostertagi infections are widespread in cattle population of Europe, however data on their prevalence in Poland are only fragmentary. Therefore, the cross-sectional study was carried out to determine the herd-level seroprevalence of $F$. hepatica and O. ostertagi infection in dairy cattle population in the central and north-eastern provinces Poland, and to identify basic local risk factors for these infections. In total, 598 herds were enrolled, 394 (65.9\%) in the north-eastern province and 204 (34.1\%) in the central province. In each herd the questionnaire survey was conducted and bulk-tank milk (BTM) sample was collected and screened using two indirect immunoenzymatic tests. Optical density ratio (ODR) was regarded as the quantitative proxy of exposure to either of the two parasites.
\end{abstract}

Results: Both Fasciola and Ostertagia ELISA ODR in the north-eastern province was significantly higher than ODR in the central province. At the cut-off value of ODR $=0.27$ the true herd-level seroprevalence of $F$. hepatica was $79.6 \%(95 \% \mathrm{Cl}$ : $74.0 \%, 84.3 \%)$ in the north-eastern province and $13.0 \%$ (95\% Cl: 5.3\%, 21.7\%) in the central province. At the cut-off of $\mathrm{ODR}=0.50151$ of 188 herds $(80.3 \%, 95 \% \mathrm{Cl}: 74.1 \%, 85.4 \%)$ were seropositive for 0 . ostertagi in the north-eastern province and only 70 of 136 herds $(51.5 \%, 95 \% \mathrm{Cl}: 43.1 \%, 59.7 \%)$ were seropositive in the central province. Location of a herd in the north-eastern province, longer grazing period practiced in a herd and $>50 \%$-share of grazing grass in roughage were all positively related to the increase in exposure to both parasites. Moreover, the use of hay or haylage as main roughage proved to be positively related to the increase in exposure to $F$. hepatica.

Conclusions: F. hepatica and O. ostertagi are widespread in cattle population in Poland, however their occurrence at a herd-level varies between different regions of Poland. This diversity can only partly be explained by different herd management, and appears linked to environmental and climate conditions typical for these regions.

Keywords: Bulk-tank milk, ELISA, Grazing, Hay, Haylage

\footnotetext{
* Correspondence: mczopowicz@gmail.com

${ }^{1}$ Laboratory of Veterinary Epidemiology and Economics, Faculty of Veterinary Medicine, Warsaw University of Life Sciences, Nowoursynowska 159c, 02-776 Warsaw, Poland

Full list of author information is available at the end of the article
}

(c) The Author(s). 2018 Open Access This article is distributed under the terms of the Creative Commons Attribution 4.0 International License (http://creativecommons.org/licenses/by/4.0/), which permits unrestricted use, distribution, and reproduction in any medium, provided you give appropriate credit to the original author(s) and the source, provide a link to the Creative Commons license, and indicate if changes were made. The Creative Commons Public Domain Dedication waiver (http://creativecommons.org/publicdomain/zero/1.0/) applies to the data made available in this article, unless otherwise stated. 


\section{Background}

Parasitic diseases have great impact on cattle productivity and welfare in all regions of the world [1]. Infections with two groups of internal parasites - liver flukes and gastrointestinal nematodes - are commonly regarded as most detrimental for dairy cattle [2, 3]. The former group is represented in Europe by an ubiquitous fluke Fasciola hepatica, responsible for fascioliasis - a disease usually following a chronic course in cattle and known to reduce both the milk yield and quality [4]. Gastrointestinal nematodes are a very diverse group of roundworms of which Ostertagia ostertagi, responsible for pathologic lesions in the abomasum, appears to be of main importance in the temperate climate zone $[5,6]$.

Both $F$. hepatica and $O$. ostertagi infections are widespread in cattle population of Europe. Herd-level prevalence of $F$. hepatica infection ranges from below $10 \%$ in Sweden to almost $90 \%$ in Wales $[3,7,8]$. Intensity of exposure to O. ostertagi expressed as a quantitative result of bulk tank milk ELISA shows similar spatial trends [9-11] with over $90 \%$ of affected herds in Great Britain [12]. Similar risk factors have so far been identified for both infections with access to pastures, grazing season length and climate conditions, especially frequent rainfalls, being the most commonly mentioned $[9,11,13-17]$.

Latest spatial analysis indicated Poland as the region with low-to-moderate risk of exposure to $F$. hepatica with the north-eastern part of the country as potentially the high-risk area [14]. Observations from the second half of the twentieth century appear to corroborate this result [18], however, recent large-scale studies allowing to verify this model are lacking. The snail Galba truncatula, an intermediate host of $F$. hepatica, is widespread in Poland and appears to be quite often a source of cercariae [19]. F. hepatica infection has been diagnosed at individual-animal level in 4-20\% cows in north-eastern regions using fecal egg count [20], in 5-65\% cows in the south-eastern province and $28 \%$ in the southern province of Poland on the basis of post-slaughter examinations [21-24] and in $20-50 \%$ cows in central and eastern regions using PCR for fecal samples [25]. However, no herd-level disease survey based on bulk-tank milk testing has so far been published. On the other hand, two studies carried out in cattle herds in the southern Poland $[26,27]$ showed presence of $O$. ostertagi antibodies in bulk-tank milk of all herds enrolled, with 30$56 \%$ herds considered as economically affected by the infection. No data on O. ostertagi prevalence from other parts of Poland are available.

Therefore, we decided to carry out the cross-sectional study to determine the herd-level seroprevalence of $F$. hepatica and O. ostertagi infection in dairy cattle population in the central and north-eastern Poland, and to identify basic local risk factors for these infections.

\section{Methods}

\section{Herds and questionnaires}

The study was carried out in summer 2012 and 2013 in 2 of 16 Polish provinces - Podlaskie province located in the north-eastern part of the country and Łódzkie province situated in the central Poland. Herds were selected from the lists of farmers who used to sell milk to five large dairies located in the north-eastern (3 dairies) and the central province ( 2 dairies) and they were enrolled in the study provided that they counted at least 10 adult cows ( $>24$ month-old) and their owners granted informed verbal consent for participation in the study. Given that the estimated parameter in this study was the quantitative result of an immunoenzymatic test (optical density ratio, ODR), only the lower limit of the sample size required (n) was determined at the $95 \%$ level of confidence according to the following formula: $n=(1$. $96 \times \sigma)^{2} / \mathrm{M}^{2}$, where $\sigma^{2}$ stood for the variance in the population and $M$ was the desired size of the $95 \%$ margin of error (precision). The minimum required sample size was determined so that the desired precision of the estimation (M) was not lower than $20 \%$ of the dispersion of observed ODRs $\left(\sigma^{2}\right)$ and equaled 97 herds.

Each herd was visited once in 2012 or 2013. During the visit bulk-tank milk (BTM) samples were collected and the questionnaire survey was conducted personally by the author (SJK). The questionnaire had been developed specifically for this study (Additional file 1) and it included following information: herd size (only adult dairy cows), average milk yield per lactation, grazing policy (recorded as no grazing, grazing roughly half a day, roughly whole day or whole $24 \mathrm{~h}$ ), length of grazing period (in months), main roughage used (corn silage, haylage or hay), proportion of grazing grass in diet (no grazing grass, $<50 \%$ of all roughage, $>50 \%$ of all roughage), and treatment against worms used in the herd. The study complied with the Directive 2010/63/EU and the Act of Polish Parliament of 15 January 2015 on protection of animals used for scientific purposes. According to Polish legal regulations no formal approval of the ethical commission regarding participation of cattle herd owners in the study (completing questionnaires) was required since questionnaires applied to animal not human health (verbal information from the National Ethical Commission).

\section{Bulk-tank milk sampling and serological tests}

Bulk-tank milk (BTM) samples were collected into $50 \mathrm{ml}$ Falcon with 1 sodium azide tablet per falcon and centrifuged for $15 \mathrm{~min}$. at $1200 \times \mathrm{g}$ in a cooling centrifuge set to $4{ }^{\circ} \mathrm{C}$. Then, the fat fraction was carefully moved to the side with the plastic spatula, and the whey fraction was collected with a plastic Pasteur pipette, aliquoted into $2 \mathrm{ml}$ Eppendorf tubes and stored at $-20{ }^{\circ} \mathrm{C}$ until testing. 
Then, BTM samples were screened using two semiquantitative indirect immunoenzymatic tests from Boehringer Ingelheim Svanova, Sweden: SVANOVIR ${ }^{\circ}$. hepatica-Ab (all samples), based on excretory and secretory antigens (E/S ELISA), and SVANOVIR O.ostertagi-Ab (only samples collected in 2013). ELISAs were performed according to manufacturer's manuals. The results were expressed as optical density (OD) ratio (ODR) calculated with the following formula:

$$
\begin{aligned}
& O D R=\left(O D_{B T M} \text { sample }-O D_{\text {negative control }}\right) /\left(O D_{\text {positive }}\right. \\
& \text { control }-O D_{\text {negative control }}
\end{aligned}
$$

ODR was regarded as the quantitative proxy of exposure to either of the two parasites.

To report herd-level seroprevalences for the infections some cut-offs must have been assumed. For F. hepatica we set the cut-off value at $\mathrm{ODR}=0.27$ as for this figure sensitivity and specificity for identifying herds in which more than $25 \%$ of the cows were infected was known and equaled 96\% (95 CI: 89\%, 100\%) and 80\% (95 CI: $66 \%, 94 \%)$, respectively [8]. Within-herd prevalence of $F$. hepatica of at least $25 \%$ had been in turn previously proposed as a threshold for significant production losses [28]. Furthermore, we used the cut-off values recommended by the manufacturer to identify herds affected by $F$. hepatica at low (economically insignificant) or high (economically significant) level, which equaled $\mathrm{ODR}=0$. 30 and $\mathrm{ODR}=0.60$, respectively.

For O. ostertagi we assumed the cut-off recommended by the manufacturer, which equaled ODR $=0.50$, and allowed to identify herds economically affected by the parasite.

Nevertheless, all risk analyses were performed using the crude ODRs instead of categorical results based on the aforementioned cut-off values, in order to retain as much information as possible.

\section{Statistical analysis}

Numerical variables were presented as the median, interquartile range (IQR) and range, categorical variables as the count and percentage in the group. Ninety five per cent confidence intervals ( $95 \% \mathrm{CI}$ ) for the apparent and true prevalence were determined using the Wilson's score method. Mean ODRs (standard deviation, SD) were also reported to allow comparisons with other studies, however all statistical analyses were non-parametric as ODRs were non-normally distributed according to the ShapiroWilk test $(p<0.001$ for ODRs of both ELISAs except for ODR of Ostertagia ELISA in the central province where $p$ $=0.201$ ). In the univariable analysis ODR was correlated with numerical variables using the Spearman's rankordered correlation coefficient $\left(\mathrm{r}_{\mathrm{s}}\right)$, and compared between two groups of a categorical variable using the MannWhitney $U$ test, or between more than 2 groups of a categorical variable using the Kruskal-Wallis test with Dunn's post-hoc test. Variables identified as linked with ODR at $p$-value below 0.1 in the univariable analysis were offered to the multivariable linear regression analysis on the basis of the backward stepwise procedure. As correlations between explanatory variables were observed, only the one showing stronger link with ODR was entered into the multivariable analysis. Proportion of ODR variation explained by the model was determined by the coefficient of determination adjusted by the number of explanatory variables included in the model (adjusted- $\mathrm{R}^{2}$ ). All statistical tests were two-sided. A significance level $(\alpha)$ was set at 0 . 05. Statistical analyses were performed in Statistica 12 (StatSoft Inc.) and the figure in the Microsoft Office Excel.

\section{Results}

In total, 598 herds were visited, 274 (45.8\%) in 2012 and $324(54.2 \%)$ in 2013. Of them 394 (65.9\%) herds were located in the north-eastern province and 204 (34.1\%) in the central province. Herd size ranged from 10 to 109 adult dairy cows and herds were larger in the northeastern (median of 24, IQR from 17 to 32 heads) than in the central province (median of 18, IQR from 14 to 25 heads) $(p<0.001)$. Of herds tested in 2013188 (58.0\%) were located in the north-eastern province and 136 (42. $0 \%$ ) in the central province. Detailed characteristics of herds from both provinces are given in Table 1 and Additional file 2. In any herd neither regular deworming of adult cows was practiced nor any medicine against parasites had been given for at least 3 months preceding sample collection.

Fasciola ELISA ODR in the north-eastern province ranged from 0.062 to 1.516 , with the median of 0.596 and IQR from 0.332 to 0.764 , and was significantly higher than ODR in the central province which ranged from 0.002 to 0.989 , with the median of 0.146 and IQR from 0.098 to $0.334(p<0.001)$. Mean ODRs (SD) were $0.553(0.266)$ and $0.235(0.206)$, respectively.

At the cut-off of ODR $=0.27378$ herds $(63.2 \%)$ tested positive for $F$. hepatica, however there was a substantial discrepancy between provinces: as many as 317 of 394 herds $(80.5 \%)$ were positive in the north-eastern province and only 61 of $204(29.9 \%)$ were positive in the central province. The overall (common for both provinces) true herd-level seroprevalence was 56.9\% (95\% CI: 52.9\%, 60.8\%) , but it was $79.6 \%$ (95\% CI: $74.0 \%, 84.3 \%)$ in the northeastern province and $13.0 \%$ (95\% CI: 5.3\%, 21.7\%) in the central province. Also much higher percentage of herds were economically affected by $F$. hepatica infection according to the manufacturer's cut-offs in the north-eastern province (Fig. 1).

Ostertagia ELISA ODR in the north-eastern province ranged from 0.010 to 1.080 , with the median of 0.725 and IQR from 0.570 to 0.845 , and was significantly higher than ODR in the central province, which ranged from 0.010 to 1.040 , with the median of 0.505 and IQR 
Table 1 Characteristics of herds included in the study given as the median, interquartile range and range or as the count and percentage of the entire group

\begin{tabular}{|c|c|c|c|c|}
\hline & Entire study population & Province & & $p$ \\
\hline & & $\begin{array}{l}\text { north-eastern (Podlaskie) } \\
(n=394)\end{array}$ & $\begin{array}{l}\text { central (Łódzkie) } \\
(n=204)\end{array}$ & \\
\hline Herd size & $21,15-30(10-109)$ & $24,17-32(10-109)$ & $18,14-25(10-100)$ & $<0.001$ \\
\hline Average milk yield & $\begin{array}{l}5500,460-6400 \\
(1700-10,200)\end{array}$ & $\begin{array}{l}5500,4500-6400 \\
(1700-10,200)\end{array}$ & $\begin{array}{l}5200,4800-6150 \\
(3000-9360)\end{array}$ & 0.982 \\
\hline Grazing policy & & & & $<0.001$ \\
\hline No grazing & $264(44.2 \%)$ & $118(30.0 \%)$ & $146(71.6 \%)$ & \\
\hline 6 h a day & $66(11.0 \%)$ & $46(11.7 \%)$ & $20(9.8 \%)$ & \\
\hline $12 \mathrm{~h}$ a day & $179(29.9 \%)$ & $156(39.6 \%)$ & $23(11.3 \%)$ & \\
\hline 24 h a day & $89(14.9 \%)$ & $74(18.7 \%)$ & $15(7.3 \%)$ & \\
\hline Length of grazing period in months (only grazed herds) & $5(1-8)$ & $5(1-8)$ & $5(1-7)$ & 0.023 \\
\hline Main roughage & & & & $<0.001$ \\
\hline Haylage & $311(52.0 \%)$ & $273(69.3 \%)$ & $38(18.6 \%)$ & \\
\hline Corn silage & $263(44.0 \%)$ & $103(26.1 \%)$ & $160(78.4 \%)$ & \\
\hline Hay & $24(4.0 \%)$ & $18(4.6 \%)$ & $6(3.0 \%)$ & \\
\hline Proportion of grazing grass in diet & & & & $<0.001$ \\
\hline No grazing grass & $203(33.9 \%)$ & $90(22.8 \%)$ & $113(55.4 \%)$ & \\
\hline Grazing grass $<50 \%$ of all roughage & $204(34.1 \%)$ & $135(34.3 \%)$ & 69 (33.1\%) & \\
\hline Grazing grass $>50 \%$ of all roughage & $191(32.0 \%)$ & 169 (42.9\%) & $22(11.5 \%)$ & \\
\hline
\end{tabular}

from 0.335 to $0.710(p<0.001)$. Mean ODRs (SD) were $0.680(0.242)$ and $0.513(0.248)$, respectively.

At the cut-off of ODR $=0.50221$ of 324 tested herds (68.2\%, 95\% CI: 63.0\%, 73.0\%) were positive for O. ostertagi, however there was also a great discrepancy between provinces: as many as 151 of 188 herds (80.3\%, 95\% CI: $74.1 \%, 85.4 \%)$ were positive in the north-eastern province and only 70 of 136 herds (51.5\%, 95\% CI: 43.1\%, 59.7\%) were positive in the central province.

Seven and 6 variables were initially offered to the multivariable model for $F$. hepatica (Additional file 3)

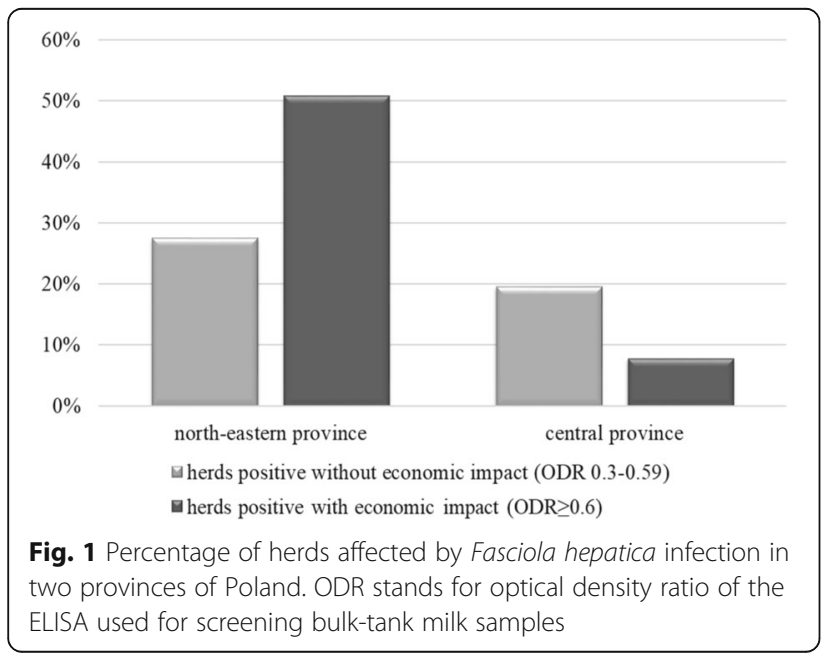

and O. ostertagi exposure (Additional file 4), respectively. Location of a herd in the north-eastern province, longer grazing period practiced in a herd and over 50\%share of grazing grass in roughage were all positively related to the increase in exposure to both $F$. hepatica and O. ostertagi (Tables 2 and 3). Moreover, the use of hay or haylage as main roughage was positively related to the increase in exposure to F. hepatica (Table 2). The models including the aforementioned variables explained only $38.1 \%$ and $33.6 \%$ of variation of exposure to $F$. hepatica and $O$. ostertagi, respectively.

Fasciola ELISA ODR and Ostertagia ELISA ODR were moderately positively correlated with each other in both provinces (the north-eastern province $\mathrm{r}_{\mathrm{s}}=0.45, p<0.001$, $n=188$; the central province $\mathrm{r}_{\mathrm{s}}=0.58, p<0.001, n=136$ ).

\section{Discussion}

Our study shows that both F. hepatica and O. ostertagi infection is widespread in Polish cattle population, and the north-eastern part of the country appears a high-risk area for both infections.

It is difficult to compare herd-level seroprevalence of F. hepatica from our study with the results of studies from other countries since various methods such as coproantigen ELISA [29], f2-antigen- or cathepsin L1 antigen-based serum ELISA [17, 30, 31], post-slaughter examinations [32], or combinations of the aforementioned [33] have been used, and marked differences in 
Table 2 Multivariable linear regression model for herd-level exposure to Fasciola hepatica

\begin{tabular}{|c|c|c|c|c|}
\hline Risk factor & $\begin{array}{l}\text { Regression coefficient (B) } \\
\text { and standard error (SE) }\end{array}$ & $\begin{array}{l}95 \% \text { confidence interval }(95 \% \mathrm{Cl}) \\
\text { for regression coefficient }\end{array}$ & t-statistics & $p$-value \\
\hline Intercept & $0.18(0.02)$ & - & - & - \\
\hline The north-eastern province & $0.21(0.02)$ & $0.17,0.26$ & 9.05 & $<0.001^{a}$ \\
\hline Length of grazing period (months) & $0.03(0.01)$ & $0.02,0.04$ & 6.35 & $<0.001^{\mathrm{a}}$ \\
\hline Grazing grass $>50 \%$ of all roughage & $0.08(0.02)$ & $0.04,0.13$ & 3.38 & $0.001^{\mathrm{a}}$ \\
\hline Hay or haylage as main roughage & $0.05(0.02)$ & $0.01,0.09$ & 2.03 & $0.043^{a}$ \\
\hline Grazing on pasture $>6 \mathrm{~h}$ & $0.06(0.03)$ & $-0.01,0.12$ & 1.67 & 0.095 \\
\hline Any grazing grass in roughage & $-0.03(0.03)$ & $-0.08,0.03$ & -0.89 & 0.373 \\
\hline Grazing on pasture & $0.03(0.07)$ & $-0.11,0.17$ & 0.38 & 0.706 \\
\hline
\end{tabular}

a significant risk factor for herd-level exposure to Fasciola hepatica at a significance level of 0.05

their diagnostic performance have recently been demonstrated [34, 35]. Even if the same E/S ELISA had been used the authors assumed different cut-off values [7, 15, 35, 36]. We based our interpretation of Fasciola ELISA ODR on logical argumentation of Vercruysse and Claerebout [28] and Salimi-Bejestani et al. [8] - the cut-off of ODR $=0.27$ allows to detect herds in which at least one fourth of cows is infected by $F$. hepatica, which is considered an economically significant level. Following this interpretation the north-eastern part of our country seems to be as much affected as England, Scotland and Wales (76-86\%; [37]). In the Belgian and German studies $[36,38]$ much higher cut-off of ODR $=0.8$ was used and the herd-level seroprevalences were $37 \%$ and 50 $57 \%$, respectively. If the cut-off of ODR $=0.27$ had been assumed these figures perhaps would have been much higher, which implies that situation in the central part of Poland is better than in other countries of the western Europe. It seems to be more like in low-risk Scandinavian countries [7].

Median Ostertagia ELISA ODR in the central province of Poland (0.51, IQR from 0.34 to 0.71 ) was similar or slightly higher than the figures presented in two other studies carried out in the southern province $[26,27]$ which were 0.59 (IQR from 0.37 to 0.66 ) and 0.29 (IQR from 0. 12 to 0.59 ), respectively. In the north-east median
Ostertagia ELISA ODR (0.73, IQR from 0.57 to 0.85 ) was much higher than in the southern and central provinces. The same trend can be observed for the herd-level seroprevalence at the cut-off set to ODR of $0.5-30-56 \%$ in the south, $50 \%$ in the center and $80 \%$ in the north-east of the country. These results confirm that the north-east of Poland is a high-risk area. In general, situation in Poland corresponds to other European countries with the central part of the country closer to countries with moderate exposure like France, Germany, Denmark, Sweden and Netherlands, and the north-eastern part more like highrisk countries such as Belgium, UK, Ireland and Switzerland $[9,10,17,39]$. Nevertheless, the conclusions on the economic role of $O$. ostertagi should be drawn with caution as the antigen used for the Ostertagia ELISA is considered to cross-react with antibodies to several other parasites including Cooperia spp. [40], F. hepatica and lungworm Dictyocaulus viviparus [35]. Given that these parasites differ considerably from $O$. ostertagi, Ostertagia ELISA is likely to cross-react with antibodies against any members of Trichostrongyloidea superfamily or against Paramphistomidae family (rumen flukes). In our study quantitative results of ELISAs for F. hepatica and O. ostertagi were also mutually correlated which may at least partly be explained by overlapping risk factors for both infections, however the role of cross-reactions can neither

Table 3 Multivariable linear regression model for herd-level exposure to Ostertagia ostertagi

\begin{tabular}{|c|c|c|c|c|}
\hline Risk factor & $\begin{array}{l}\text { Regression coefficient (B) } \\
\text { and standard error (SE) }\end{array}$ & $\begin{array}{l}95 \% \text { confidence interval }(95 \% \mathrm{Cl}) \\
\text { for regression coefficient }\end{array}$ & t-statistics & $p$-value \\
\hline Intercept & $0.42(0.02)$ & - & - & - \\
\hline Length of grazing period (months) & $0.05(0.01)$ & $0.03,0.06$ & 8.40 & $<0.001^{b}$ \\
\hline Grazing grass $>50 \%$ of all roughage & $0.08(0.03)$ & $0.02,0.13$ & 2.60 & $0.010^{b}$ \\
\hline The north-eastern province & $0.06(0.03)$ & $0.01,0.11$ & 2.24 & $0.026^{b}$ \\
\hline Grazing on pasture & $-0.16(0.08)$ & $-0.31,-0.01$ & -1.98 & $0.048^{\mathrm{a}}$ \\
\hline Hay or haylage as main roughage & $-0.02(0.03)$ & $-0.07,0.04$ & -0.50 & 0.620 \\
\hline Herd size & $0.01(0.01)$ & $-0.01,0.01$ & -0.11 & 0.912 \\
\hline
\end{tabular}

a excluded for very strong correlation with the length of grazing period.

${ }^{b}$ significant risk factor for herd-level exposure to Ostertagia ostertagi at a significance level of 0.05 . 
be excluded nor reliably assessed. Similar doubts have also been raised by other authors $[17,36]$. Therefore, Ostertagia ELISA may have overestimated the true level of infestation with $O$. ostertagi in Polish cattle herds. Nevertheless, our results are comparable with studies carried out in other regions as the same ELISA has been used worldwide.

All included risk factors were more often encountered in the north-eastern province, which might have accounted for the higher prevalence of both infections. Nevertheless, the location of a cattle herd in this region still proved to be an independent risk factor for both infections when the model was adjusted by all the other risk factors. This likely rises from climatic differences between central and northeastern Poland, mainly higher average monthly rainfalls in the spring and early summer in the north Poland [41], which has been previously shown to explain a considerable part of variation of $F$. hepatica occurrence [42-44].

Risk factors identified in our study generally match to these already known. Length of grazing period and high proportion of grazing grass in roughage have been evidenced to increase the risk of exposure to $F$. hepatica and $O$. ostertagi $[9-11,15,17]$ simply because they are pasture-borne parasites. The univariable analysis indicated that herd size was negatively linked to the risk of exposure to $O$. ostertagi, which was consistent with many previous studies [7, 9-11], however, this factor did not hold in the multivariable analysis. This may result from the fact that Polish herds are small compared to those included in most of other studies. On the other hand, in the recent Swiss study [17], where most of herds were similarly small, herd size proved to increase the risk of exposure to $O$. ostertagi, which indicates that the role of herd size in the epidemiology of $O$. ostertagi is unclear and any conclusion should be drawn very cautiously. Contrary to some previous studies $[11,17]$ we did not include milk yield in our risk analysis as reduced milk yield is a consequence of more intensive exposure to the parasites $[2,37,45]$ rather than a factor affecting the exposure. The only thing not mentioned before is the fact that using hay or haylage as main roughage increases risk of exposure to $F$. hepatica, when compared to corn silage, even when no pasture or fresh grass is available. This likely results from the presence of infective encysted metacercariae in forages harvested from meadows, and their resistance to the process of drying or fermentation involved in production of hay or silages. While it is known that metacercariae remain viable and infective in drying hay for at least several months, haylage has been considered as an unfavorable environment for metacercariae, which sustains their viability for less than 3 weeks [46]. Our observation seems to contradict this statement. Most likely explanation is that the viability of metacercariae depends on the quality of fermentation process. The process of haylage preparation in field conditions simply may not be as careful as it was in the experimental study [46], which allows metacercariae to remain viable and infective. Corn silage is safer perhaps because environmental conditions on corn fields are less favorable for metacerkariae survival than on grass pastures [47]. Moreover, corn for silage is harvested at considerably higher cutting height (usually more than $20 \mathrm{~cm}$ from the ground) than hay for haylage $(8-10 \mathrm{~cm})$. This may reduce the risk of inclusion of metacercariae in the roughage, as they have been shown to encyst mainly on the bottom parts of plants $[48,49]$.

The main shortcoming of our study is the lack of knowledge of climate (e.g. rainfalls, temperatures) and environmental conditions (e.g. soil humidity on pastures) on farms included in the study, as well as low refinement of farm management factors (i.e. type of pasture and water source utilized, exact share of grazing grass in diet, turnover of calves and heifers, stocking density etc.), which make the risk analysis quite superficial (which is highlighted by the low amount of variation explained by the models), in particular when compared with thorough risk analyzes published in recent years [30,32, 37]. However, we mainly aimed to characterize epidemiological situation of $F$. hepat$i c a$ and $O$. ostertagi in our country, especially in view of scarcity of currently available data not only from Poland but also from our eastern neighbors. Risk analysis was rather about to confirm that factors commonly considered as linked to the occurrence of these infections play their role in Poland as well, than to find any new, so far uncovered, ones. Furthermore, herds were not randomly enrolled in this study so results should be extrapolated with caution. We hope that using lists of collaborators of main dairies and enrolling quite high proportion of herds from each province (5-10\%) at least partially compensates for lack of randomness.

\section{Conclusions}

Both F. hepatica and O. ostertagi are widespread in cattle population in Poland, however their occurrence at a herdlevel varies between different regions of Poland. This diversity can only partly be explained by different herd management, and appears linked to environmental and climate conditions typical for these regions. Our study provides basic knowledge of the epidemiological situation in the country, which is essential for effective control of those two parasitic infections in Polish cattle population.

\section{Additional files}

Additional file 1: Clean copy of the questionnaire used in this study. The questionnaire was developed specifically for this study. (DOCX $21 \mathrm{~kb}$ )

Additional file 2: Detailed data regarding cattle herds enrolled in the study. Detailed data regarding cattle herds enrolled in the study including province, optical density ratio (ODR) in Fasciola hepatica ELISA, 
result of Fasciola hepatica ELISA according to the cut-off of 0.270, optical density ratio (ODR) in Ostertagia ostertagi ELISA, result of Ostertagia ostertagi ELISA according to the cut-off of 0.50 , herd size given as the number of adult cows (> 24 month-old), average milk yield per lactation in $\mathrm{kg}$, grazing policy classed into four categories (no pasture, grazing for $6 \mathrm{~h}$ a day, for $12 \mathrm{~h}$ a day, for $24 \mathrm{~h}$ ), grazing period length in months, main roughage used in the herd (corn silage, haylage, hay), and proportion of grazing grass in diet classed into three categories (no grazing grass, $<50 \%,>50 \%$ ). (DOCX $85 \mathrm{~kb}$ )

Additional file 3: Univariable analysis of herd-level risk factors for Fasciola hepatica exposure. Descriptive statistics and results of univariable statistical analyses comparing Fasciola hepatica bulk-tank milk (BTM) optical density ratio (ODR) between cattle herds with different characteristics. (DOCX 20 kb)

Additional file 4: Univariable analysis of herd-level risk factors for Ostertagia ostertagi exposure. Descriptive statistics and results of univariable statistical analyses comparing Ostertagia ostertagi bulk-tank milk (BTM) optical density ratio (ODR) between cattle herds with different characteristics. (DOCX 20 kb)

\section{Abbreviations}

BTM: Bulk-tank milk; Cl: Confidence interval; IQR: Interquartile range; M: Desired precision of the estimation; n: Sample size required; OD: Optical density; ODR: Optical density ratio; $r_{s}$ : Spearman's rank-ordered correlation coefficient; $\sigma^{2}$ : Variance in the population

\section{Funding}

This study was financed by the European Union Seventh Framework Programme for the Research and Technological Development "GLOWORM" no. FP7-KBBE-2011-5 288975. The costs of article publication were covered by KNOW (Leading National Research Centre) Scientific Consortium "Healthy Animal - Safe Food", decision of Ministry of Science and Higher Education No. 05-1/KNOW2/2015. The funders had no role in study design, data collection and analysis, decision to publish, conclusions and preparation of the manuscript.

\section{Availability of data and materials}

All data are available in the Additional file 2. The datasets used and analyzed during the current study are available from the corresponding author on reasonable request.

\section{Authors' contributions}

SJK, MC, CNW, EM, and JK designed research; SJK, TN, CNW, EM, and AB performed research; MC, SJK, and JK analyzed data and wrote the paper. All authors read and approved the final manuscript.

\section{Ethics approva}

The study complied with the Directive 2010/63/EU and the Act of Polish Parliament of 15 January 2015 on protection of animals used for scientific purposes (Journal of Laws 2015, item 266).

Cattle herd owners granted informed verbal consent for participation in the study.

According to Polish legal regulations no formal approval of the bioethical commission regarding participation of cattle herd owners in the study (completing questionnaires) was required since questionnaires applied to animal not human health (verbal information from the National Ethical Commission on the basis of the Act of Polish Parliament of 6 September 2001 Pharmaceutical Law, Journal of Laws 2001, No. 126, item 1381, which regulates participation in medical experiments)

\section{Competing interests}

The authors declare that they have no competing interests.

\section{Publisher's Note}

Springer Nature remains neutral with regard to jurisdictional claims in published maps and institutional affiliations.

\section{Author details}

'Laboratory of Veterinary Epidemiology and Economics, Faculty of Veterinary Medicine, Warsaw University of Life Sciences, Nowoursynowska 159c, 02-776 Warsaw, Poland. ${ }^{2}$ Laboklin GmbH \& Co. KG, Steubenstrasse 4, 97688 Bad Kissingen, Germany.
Received: 15 December 2017 Accepted: 13 April 2018 Published online: 17 April 2018

\section{References}

1. Fitzpatrick JL. Global food security: the impact of veterinary parasites and parasitologists. Vet Parasitol. 2013;195:233-48.

2. Charlier J, van der Voort M, Kenyon F, Skuce P, Vercruysse J. Chasing helminths and their economic impact on farmed ruminants. Trends Parasitol. 2014;30:361-7.

3. Mehmood K, Zhang H, Sabir AJ, Abbas RZ, ljaz M, Durrani AZ, Saleem MH, Ur Rehman M, labal MK, Wang Y, Ahmad HI, Abbas T, Hussain R, Ghori MT, Ali S, Khan AU, Li J. A review on epidemiology, global prevalence and economical losses of fasciolosis in ruminants. Microb Pathog. 2017;109:253-62.

4. Mezo M, González-Warleta M, Castro-Hermida JA, Muiño L, Ubeira FM. Association between anti-F. hepatica antibody levels in milk and production losses in dairy cows. Vet Parasitol. 2011;180:237-42.

5. Bellet C, Green MJ, Vickers M, Forbes A, Berry E, Kaler J. Ostertagia spp., rumen fluke and liver fluke single- and poly-infections in cattle: an abattoir study of prevalence and production impacts in England and Wales. Prev Vet Med. 2016;132:98-106.

6. Fanke J, Charlier J, Steppin T, von Samson-Himmelstjerna G, Vercruysse J, Demeler J. Economic assessment of Ostertagia ostertagi and Fasciola hepatica infections in dairy cattle herds in Germany using Paracalc $<$ sup $>^{\oplus}<$ / sup>. Vet Parasitol. 2017;240:39-48.

7. Höglund J, Dahlstrom F, Engstrom A, Hessle A, Jakubek E-B, Schnieder T, Strube C, Sollenberg S. Antibodies to major pasture borne helminth infections in bulk-tank milk samples from organic and nearby conventional dairy herds in south-central Sweden. Vet Parasitol. 2010;171:293-9.

8. Salimi-Bejestani MR, Daniel RG, Felstead SM, Cripps PJ, Mahmoody H, Williams DJ. Prevalence of Fasciola hepatica in dairy herds in England and Wales measured with an ELISA applied to bulk-tank milk. Vet Rec. 2005;156:729-31.

9. Forbes $A B$, Vercruysse J, Charlier J. A survey of the exposure to Ostertagia ostertagi in dairy cow herds in Europe through the measurement of antibodies in milk samples from the bulk tank. Vet Parasitol. 2008;157:100-7.

10. Bennema SC, Vercruysse J, Morgan E, Stafford K, Höglund J, Demeler J, von Samson-Himmelstjerna G, Charlier J. Epidemiology and risk factors for exposure to gastrointestinal nematodes in dairy herds in northwestern Europe. Vet Parasitol. 2010;173:247-54.

11. Pablos-Tanarro A, Pérez-Cabal MÁ, Ortega-Mora LM, Ferre I. Presence of Ostertagia ostertagi antibodies in bulk tank milk from cattle herds in northern Spain. Vet Parasitol. 2013;197:388-92.

12. Velasova M, Damaso A, Prakashbabu BC, Gibbons J, Wheelhouse N, Longbottom D, Van Winden S, Green M, Guitian J. Herd-level prevalence of selected endemic infectious diseases of dairy cows in Great Britain. J Dairy Sci. 2017;100:9215-33.

13. Charlier J, Ghebretinsae AH, Levecke B, Ducheyne E, Claerebout E, Vercruysse J. Climate-driven longitudinal trends in pasture-borne helminth infections of dairy cattle. Int J Parasitol. 2016;46:881-8.

14. Ducheyne E, Charlier J, Vercruysse J, Rinaldi L, Biggeri A, Demeler J, Brandt C, De Waal T, Selemetas N, Höglund J, Kaba J, Kowalczyk SJ, Hendrickx G. Modelling the spatial distribution of Fasciola hepatica in dairy cattle in Europe. Geospat Health. 2015;9:261-70.

15. Novobilský A, Sollenberg S, Höglund J. Distribution of Fasciola hepatica in Swedish dairy cattle and associations with pasture management factors. Geospat Health. 2015;9:293-300.

16. Okulewicz $\mathrm{A}$. The impact of global climate change on the spread of parasitic nematodes. Ann Parasitol. 2017;63:15-20.

17. Frey CF, Eicher R, Raue K, Strube C, Bodmer M, Hentrich B, Gottstein B, Marreros N. Apparent prevalence of and risk factors for infection with Ostertagia ostertagi, Fasciola hepatica and Dictyocaulus viviparus in Swiss dairy herds. Vet Parasitol. 2018;250:52-9.

18. Deryło A, Szilman P. Exensivity of invasion Fasciola hepatica L. in cattle in the period 1957-1998 and valuation of losses caused by staggers disease among cattle in Poland, 1995-1997 (in Polish). Wiad Parazytol. 1999:45:169-79.

19. Kozak M, Wędrychowicz $H$. The performance of a PCR assay for field studies on the prevalence of Fasciola hepatica infection in Galba truncatula intermediate host snails. Vet Parasitol. 2010;168:25-30.

20. Michalski M, Romaniuk K. Liver fluke (Fasciola hepatica $\mathrm{L}$ ) in dairy cows in north-east Poland (in Polish). Med Weter. 2000;56:182-4. 
21. Deryło A, Kozłowska-Łój J, Szilman P, Najda N, Seniuk A, Wasilewski K. Extensivity of infection of Fasciola hepatica L. in cattle in Lublin's voivodship in the years 1993-2001 (in Polish). Wiad Parazytol. 2001;47:775-8.

22. Kornaś S, Nowosad B, Skalska M, Wróbel A. Dairy cattle infection with Fasciola hepatica in small farms. Med Weter. 2005;61:1368-9.

23. Kozłowska-Łój J. Prevalence of Fasciola hepatica L. infection in cattle in the Lublin province (Poland) in the years 2005-2008 (in Polish). Wiad Parazytol. 2011;57:127-8

24. Kozłowska-Łój J, Łój-Maczulska A. The prevalence of Fasciola hepatica L. infection in cattle in the Lublin province in the years 2009-2012. Ann Parasitol. 2013;59:207-8.

25. Kozak-Cieszczyk M. The occurrence of Fasciola hepatica in chosen regions of Poland based on molecular and serological methods (in Polish). Wiad Parazytol. 2006;52:137-9.

26. Płoneczka-Janeczko K, Piekarska J, Rypuła K, Mazurkiewicz M. A survey of anti-Ostertagia ostertagii antibody levels in bulk tank milk samples (BTM) in dairy herds in lower Silesia region (Poland). Pol J Vet Sci. 2011;14:135-6.

27. Piekarska J, Płoneczka-Janeczko K, Kantyka M, Kuczaj M, Gorczykowski M, Janeczko K. Gastrointestinal nematodes in grazing dairy cattle from small and medium-sized farms in southern Poland. Vet Parasitol. 2013;198:250-3.

28. Vercruysse J, Claerebout E. Treatment vs. non-treatment of helminth infections in cattle: defining the threshold. Vet Parasitol. 2001;98:195-214.

29. Cringoli G, Rinaldi L, Veneziano V, Capelli G, Malone JB. A cross-sectional coprological survey of liver flukes in cattle and sheep from an area of the southern Italian Apennines. Vet Parasitol. 2002;108:137-43.

30. Bloemhoff Y, Forbes A, Danaher M, Good B, Morgan E, Mulcahy G, Sekiya M, Sayers R. Determining the prevalence and seasonality of Fasciola hepatica in pasturebased dairy herds in Ireland using a bulk tank milk ELISA. Ir Vet J. 2015;68:16

31. Munita MP, Rea R, Bloemhoff Y, Byrne N, Martinez-lbeas AM, Sayers RG. Sixyear longitudinal study of Fasciola hepatica bulk milk antibody ELISA in the dairy dense region of the Republic Ireland. Prev Vet Med. 2016;134:16-25.

32. Olsen A, Frankena $\mathrm{K}$, Bødker $\mathrm{R}$, Toft N, Thamsborg SM, Enemark HL, Halasa T. Prevalence, risk factors and spatial analysis of liver fluke infections in Danish cattle herds. Parasit Vectors. 2015:8:160.

33. Innocent GT, Gilbert L, Jones EO, McLeod JE, Gunn G, McKendrick IJ, Albon SD. Combining slaughterhouse surveillance data with cattle tracing scheme and environmental data to quantify environmental risk factors for liver fluke in cattle. Front Vet Sci. 2017;4:65.

34. Arifin Ml, Höglund J, Novobilský A. Comparison of molecular and conventional methods for the diagnosis of Fasciola hepatica infection in the field. Vet Parasitol. 2016;232:8-11.

35. Mazeri S, Sargison N, Kelly RF, Bronsvoort BM, Handel I. Evaluation of the performance of five diagnostic tests for Fasciola hepatica infection in naturally infected cattle using a Bayesian no gold standard approach. PLoS One. 2016;11:e0161621.

36. Bennema S, Vercruysse J, Claerebout E, Schnieder T, Strube C, Ducheyne E, Hendrickx G, Charlier J. The use of bulk-tank milk ELISAs to assess the spatial distribution of Fasciola hepatica, Ostertagia ostertagi and Dictyocaulus viviparus in dairy cattle in Flanders (Belgium). Vet Parasitol. 2009;165:51-7.

37. Howell A, Baylis M, Smith R, Pinchbeck G, Williams D. Epidemiology and impact of Fasciola hepatica exposure in high-yielding dairy herds. Prev Vet Med. 2015;121:41-8.

38. Kuerpick B, Schnieder T, Strube C. Seasonal pattern of Fasciola hepatica antibodies in dairy herds in northern Germany. Parasitol Res. 2012;111:1085-92.

39. Charlier J, Claerebout E, Duchateau L, Vercruysse J. A survey to determine relationships between bulk tank milk antibodies against Ostertagia ostertagi and milk production parameters. Vet Parasitol. 2005;129:67-75.

40. Keus A, Kloosterman A, Van Den Brink R. Detection of antibodies to Cooperia spp. and Ostertagia spp. in calves with the enzyme linked immunosorbent assay (ELISA). Vet Parasitol. 1981;8:229-36.

41. Czarnecka M, Nidzgorska-Lencewicz J. Multiannual variability of seasonal precipitation in Poland (in Polish). Water Environ Rural Areas. 2012;12:45-60.

42. Bennema SC, Ducheyne E, Vercruysse J, Claerebout E, Hendrickx G, Charlier J. Relative importance of management, meteorological and environmental factors in the spatial distribution of Fasciola hepatica in dairy cattle in a temperate climate zone. Int J Parasitol. 2011:41:225-33.

43. Mas-Coma S, Valero MA, Bargues MD. Climate change effects on trematodiases, with emphasis on zoonotic fascioliasis and schistosomiasis. Vet Parasitol. 2009;163:264-80.

44. McCann CM, Baylis M, Williams DJL. The development of linear regression models using environmental variables to explain the spatial distribution of
Fasciola hepatica infection in dairy herds in England and Wales. Int J Parasitol. 2010:40:1021-8.

45. Köstenberger K, Tichy A, Bauer K, Pless P, Wittek T. Associations between fasciolosis and milk production, and the impact of anthelmintic treatment in dairy herds. Parasitol Res. 2017;116:1981-7.

46. Tarczyński S, Podkówka W. Effect of ensilage of green roughage and drying hay on viability and infectivity of Fasciola hepatica metacercariae. Acta Parasitol. 1964;20:201-8.

47. Meek AH, Morris RS. The longevity of Fasciola hepatica metacercariae encysted on herbage. Aust Vet J. 1979;55:58-60.

48. Dreyfuss $G$, Abrous M, Vignoles P, Rondelaud D. Fasciola hepatica and Paramphistomum daubneyi: vertical distribution of metacercariae on plants under natural conditions. Parasitol Res. 2004;94:70-3.

49. Suhardono, Roberts JA, Copeman DB. Distribution of Metacercariae of Fasciola gigantica on rice straw. Trop Anim Health Prod. 2006:38:117-9.

\section{Ready to submit your research? Choose BMC and benefit from:}

- fast, convenient online submission

- thorough peer review by experienced researchers in your field

- rapid publication on acceptance

- support for research data, including large and complex data types

- gold Open Access which fosters wider collaboration and increased citations

- maximum visibility for your research: over $100 \mathrm{M}$ website views per year

At BMC, research is always in progress.

Learn more biomedcentral.com/submissions 